\title{
Seasonal constraints on the mandible allometry of Lucanus cervus (Coleoptera: Lucanidae)
}

\author{
SöNKe HARDERSEN ${ }^{1}$, ANNA L.M. MACAGNO ${ }^{1,2}$, ROBERTo SACCHI ${ }^{3}$ and ILARIA TONI ${ }^{1}$ \\ ${ }^{1}$ Corpo Forestale dello Stato, Centro Nazionale per lo Studio e la Conservazione della Biodiversità Forestale "Bosco Fontana" di \\ Verona, Strada Mantova 29, I-46045 Marmirolo, Italy; e-mails: s.hardersen@gmail.com; anna.macagno@gmail.com; \\ ilaria_toni@vodafone.it \\ ${ }^{2}$ Dipartimento di Biologia e Biotecnologie "Charles Darwin”, Sapienza Università di Roma, Via Borelli 50, I-00161 Rome, Italy \\ ${ }^{3}$ Università di Pavia, Dipartimento di Biologia Animale, Via Ferrata 9, I-27100 Pavia, Italy; e-mail: roberto.sacchi@unipv.it
}

Key words. Allometry, Coleoptera, Lucanidae, Lucanus cervus, mandibles, season, size, time constraints

\begin{abstract}
In insects, allometries of exaggerated traits such as horns or mandibles are often considered species specific and constant during a season. However, given that constraints imposed by the advancing season affect the developmental processes of organisms, these allometries may not be fixed, and the switch point between morphs may vary between populations and within populations during a season. The hypothesis of such a seasonal variation in exaggerated traits was tested using the dimorphic males of the beetle Lucanus cervus. The remains of specimens killed by predators were collected along forest tracks from mid May to late August 2008 in a protected lowland forest in northern Italy. The largest beetles were collected in mid May and average size thereafter decreased. Males collected early in the season mostly had large mandibles (i.e. they belonged to the major morph). In contrast, late in the season the probability of finding males with large mandibles was very low. The threshold body size determining morph expression also shifted during the season. Early in the season, the threshold pronotum width for a $50 \%$ chance of developing into the major morph was $1.74 \mathrm{~cm}$, whereas later in the season it was $1.90 \mathrm{~cm}$. This shift in the threshold body size was interpreted as the effect of phenotypic plasticity in a population exposed to constraints imposed by the advancing season.
\end{abstract}

\section{INTRODUCTION}

It is generally accepted that in the Scarabaeoidea (Coleoptera) size-dependent threshold mechanisms regulate the expression of dimorphic secondary sexual traits, such as horns and mandibles (e.g. Emlen et al., 2005). The functions describing allometric relationships of such traits are often considered species specific (e.g. Knell et al., 2003; Kodric-Brown et al., 2006) and constant during a season (Kodric-Brown et al., 2006; Hongo, 2007). However, current models of threshold evolution consider the genetic threshold of each individual genotype to be fixed, while the frequency distribution of switch points between alternative morphs in a population is assumed to be continuous and normal, a feature characteristic of polygenic quantitative traits (Hazel et al., 1990; Tomkins \& Hazel, 2007). The threshold mechanism and the phenotypic alternatives it regulates are thought to be independent modules (Emlen et al., 2005): the threshold body size can therefore be subject to selection through the fitness of the alternative phenotypes (Tomkins \& Hazel, 2007) and evolve rapidly. Despite a well developed theoretical background there are only a few studies that empirically assess intra-specific variation in the threshold that regulates male dimorphic traits (Moczek, 2002, 2003; Moczek et al., 2002; Tomkins et al., 2004; Hongo, 2007). There are even fewer studies on the plastic responses of thresholds during the course of a season (but see Emlen, 1996, 1997) and the ecological factors that influence polyphenism in natural populations are largely unexplored.

Organisms adjust their phenotype to suit environmental conditions, which change with the seasons. A theoretical framework exists that describes the constraints imposed by the advancing season on the development of organisms (Rowe \& Ludwig, 1991; Abrams et al., 1996) and has been tested in a number of studies (Plaistow \& SivaJothy, 1999; Tseng, 2003; Gotthard, 2004). Rowe \& Ludwig (1991) suggest that the decline in size of insects during the emergence period is an adaptive response to the conflict between size and age. Indeed, size at metamorphosis is strongly influenced by a short "window of opportunity" for emergence. In insects, size attained during larval growth is generally directly related to adult reproductive success (Simmons \& Parker, 1992; Savalli \& Fox, 1998; Sokolovska et al., 2000; Hongo, 2007). Delaying emergence carries with it the benefits of increased size (and fitness) but at a cost of delaying reproduction as less potential mates will be available late in the season. Moreover, larval mortality is an additional cost of delaying metamorphosis and reproduction. These factors are thought to explain why early emergers are typically larger than late ones (Sweeney \& Vannote, 1978; Hardersen et al., 1999; Plaistow et al., 2005).

In general, benefits of a larger adult size are traded off against costs, such as: energy storage, immune function, developmental instability, fecundity and other variables that affect fitness (e.g. Rolff et al., 2004; Cotter et al., 2008). The effect of seasonal constraints on these traits 
has been explored in a number of studies. For example, an important component of the immune function is reduced in damselfly larvae kept under late season conditions (Rolff et al., 2004). Similarly, developmental instability (measured as fluctuating asymmetry) increases in damselfly larvae kept under late season conditions (De Block et al., 2008) and in adults caught late in the season (Hardersen, 2000). Likewise, the fecundity of females that emerge late is lower in mayflies (Sweeney \& Vannote, 1978) and beetles (Ohgushi, 1991). These observations suggest that insects emerging late in the season have less energy to spend than those emerging early, as they are forced to adjust resource allocation (growth of distinct morphological structures, energy storage, immune system, etc.) in order to maximise their fitness. The plasticity of such developmental "decisions" should be adaptive, enabling growing individuals to find the best compromise in changing environments. Thus, costly exaggerated male sexual traits, such as mandibles or horns, are expected to be influenced by constraints imposed by the advancing season, according to the handicap hypothesis (Zahavi, 1975), which assumes that sexual ornaments should show a heightened condition dependence (e.g. Bonduriansky, 2007). Consequently, the allometry of sexual traits should be particularly sensitive to resource limitations imposed by the advancing season.

In this paper, the hypothesis that seasonal constraints influence the allometric function of exaggerated sexual ornaments in males of the European Stag Beetle (Lucanus cervus Linnaeus), a species well known for its variability in mandible length (Clark, 1977), is investigated. Males of this species are dimorphic with respect to mandible development, i.e. the expression of mandibles is sizedependent and two male morphs (major and minor) coexist in natural populations (Eberhard \& Gutierrez, 1991). It is also known that in males the probability of winning fights is positively correlated with size (Lagarde et al., 2005). Surprisingly little is known about the lifehistory of $L$. cervus, and more specifically the plasticity of its life cycle traits is not well documented. One reason for this is that its subterranean larvae cannot be found without destroying the habitat (Harvey et al., 2011b). It is however known that life history characteristics, such as the duration of the larval stage, vary considerably (Harvey et al., 2011a). The larval phase of L. cervus lasts between 3 and 6 years, with the number of instars varying between 3 to 5 (Harvey et al., 2011a). Subsequent pupation and eclosion are believed to be completed in late summer to early autumn and adults emerge only in the following spring-summer (Rink \& Sinsch, 2008; Harvey et al., 2011a). However, the timing of pupation and eclosion is likely to be more variable than commonly acknowledged. Paulian (1959) states that larvae can overwinter before metamorphosis and recent observations by P. Hendriks \& M. Fremlin (2010, http://maria. fremlin.de/stagbeetles/pupation/pupation_captivity.html, last accessed on 13.iv.2011) clearly show that the hibernation of freshly metamorphosed stag beetles is not obligatory, but that the species is able to complete meta- morphosis in 15 weeks, beginning in April. This plasticity in life cycle traits of L. cervus is an important basis for this study.

In detail, the aims of this research were (1) to investigate whether male L. cervus caught late in the season differed in size from those caught early, and (2) to test whether the relative investment in mandible size varied between beetles caught late and those caught early in the season. The specific predictions were that males caught late should have smaller mandibles that are also smaller in relation to body size, because they invest less in the development of these costly weapons as the season advances.

\section{MATERIAL AND METHODS}

Large samples of live specimens of Lucanus cervus are difficult to obtain (Harvey \& Gange, 2006; pers. obs.). At Bosco Fontana (Italy, Lombardy, Mantua Province), where this study was carried out, the Hooded Crow (Corvus corone cornix Linnaeus) (Aves, Corvidae) feed on stag beetles (L. Spada pers. comm.), leaving mainly the heads and thoraces on forest tracks (Campanaro et al., in press).

From 12.-18.v.2008 (week 1) to 25.-31.viii.2008 (week 16), one of the authors (I.T.) searched for the remains of L. cervus once a week, by walking slowly along all of the forest tracks in the reserve (a total of $23 \mathrm{~km}$ ). The route walked was changed every week but included all forest tracks, thus order and time of the day on which specific tracks were searched varied nonsystematically between surveys. For every $L$. cervus found, the following data were noted: collection date, time and geographical coordinates (using a detailed map).

Heads and pronota, placed in a standard position, were photographed from a fixed distance $(41 \mathrm{~cm}$ from the focus indicator) using a Nikon D70 (Nikkor, AF Micro $105 \mathrm{~mm}$ ) digital camera. These images were used to measure the width of the pronotum, used as a proxy for body size (Emlen, 1997; Moczek et al., 2002; Lagarde et al., 2005; Hongo, 2007; Macagno et al., 2009), and mandible length. Mandible length was measured as indicated in Fig. 1 as it is well known that in some large forms there is considerable dorsoventral curvature (e.g. Clark, 1977; pers. obs.). All measurements were carried out using the programme Image J $1.40 \mathrm{~g}$. The reliability of the measurement of mandible length was tested by re-photographing and re-measuring a subset of mandibles $(n=40)$ (repeatability $=0.99, F_{39,79}=2043$, $\mathrm{p}<0.001)$.

\section{Data analysis}

In order to investigate whether the remains of males of $L$. cervus collected late in the season differed in size from those collected early, weeks in which less than 7 males were collected (i.e. weeks 1, 2, and 11-16) were excluded. This procedure led to a data set of 173 specimens. Variation in body size during the flight season was analysed by assessing the differences in mean pronotum width (log-transformed measures) among weeks using a one-way ANOVA and Tukey HSD post-hoc tests. The correlation of pronotum width with elytra length (another character commonly used as a proxy for body size) was analysed by measuring elytra length (with callipers) of all specimens with the elytra still attached to the remains.

In order to investigate the influence of season on mandible allometry the full sample, irrespective of the collection week (n $=186$ ), was used. Following Knell (2009), a log-log scatterplot of mandible length vs. pronotum width was inspected to determine whether it was a continuous relationship. In addition, four models were fitted: a simple linear regression, a quadratic 


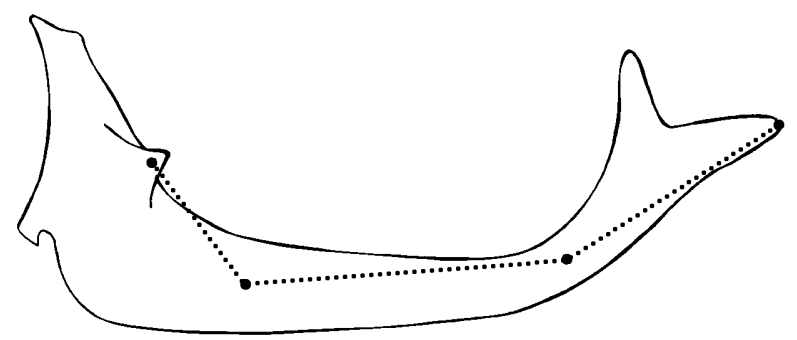

Fig. 1. Mandible length was measured as indicated by the dotted line.

model, a four-parameter sigmoidal regression (Moczek et al., 2002) and a switch point regression model. All models were computed using the software R 2.10.1 (R-Development core Team 2009) and the switch point regressions were fitted using the package Segmented (Muggeo, 2003). The AIC criterion (Akaike, 1974) was used for model comparison. Models with lower AIC scores are better descriptors of the relationship between the variables, and two models differing by less than 2 are considered to be indistinguishable from each other (Burnham \& Anderson, 2002).

As the log-log scatterplot suggested that the relationship between the two variables could be discontinuous, with some overlap in $\mathrm{x}$ and $\mathrm{y}$ variables, the dataset was checked for discontinuous allometries applying all five techniques suggested by Knell (2009). To begin with, the methods described by Eberhard \& Gutierrez (1991) and by Kotiaho \& Tomkins (2001) were used to investigate for a discontinuity in the $\mathrm{x}$ and $\mathrm{y}$ variables, respectively. Subsequently the approach described by Cook \& Bean (2006) was used to look for a discontinuous line that was not parallel to either of the two axes. As this procedure constrains the discontinuous line to pass through the origin of the axes (Knell, 2009), the technique described in Knell (2009) was used to generate a sheaf of 25 lines around the Cook \& Bean lines, in order to detect the one best separating the data into two groups. Finally, whether a model that treats the data as a mixture of two linear regressions (McLachlan \& Peel, 2000) was more appropriate was tested. As for continuous allometries, the analyses were performed using $\mathrm{R}$, and the discrete mixtures of regression models were fitted using the package Flexmix (Grün $\&$ Leisch, 2008). Significance for both discrepancy and change of slope at the switch point was tested using the partial F-test as described in Eberhard \& Gutierrez (1991). Once more, the models were compared using the AIC scores and the best fitting model was used to calculate a new factor that coded each data point as major or minor morph. This new factor was then included in a logistic regression analysis to represent the probability of the major morph being expressed by males of different sizes (Knell, 2009) and the value of the body size at which males have a $50 \%$ chance of developing into major or minor morph was used to estimate the mean of the underlying distribution threshold (Hazel et al., 1990). This analysis was carried out in $\mathrm{R}$ using a general linear model with binomial errors and a logit link where the morph (coded as major $=1$ and minor $=0$ ) was the dependent variable and the log-transformed pronotum width was the continuous explanatory variable. The same analysis was used to determine the probability of collecting a major morph during the course of the season, expressed in terms of the number of weeks that has elapsed from week 1 (12.-18.v.2008). Finally, in order to determine whether there was a shift in the threshold body size regulating morph expression during the season, the sample was split into two sub-groups of similar size (group "early" = weeks $1-6, n=87$; group "late" = weeks $7-16, n=99$ ) and for each sub-group the body size at

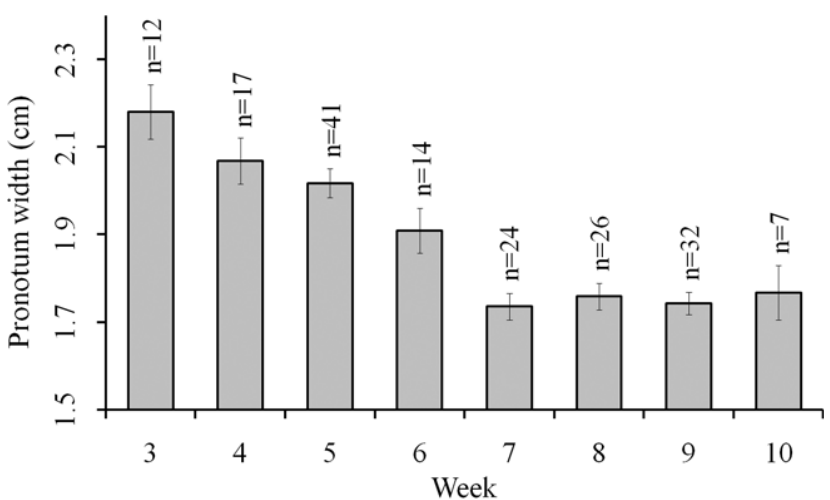

Fig. 2. Mean pronotum width $( \pm \mathrm{SE})$ of males collected in week 3 (26.v.-01.vi.2008) to week 10 (14.-20.vii.2008) ( $\mathrm{n}=$ 173). Body size decreased from week 3 to week 7 and remained constant from week 7 onwards. Number of observations are indicated above each column (e.g. $n=14)$.

which males have a $50 \%$ chance of developing into a major or minor morph was calculated separately, as explained above.

\section{RESULTS}

Pronotum width and length of elytra were closely correlated $\left(n=30, \mathrm{R}^{2}=0.888, P<0.0001\right)$. The trend in mean male body size (measured as pronotum width, PW) during the flight season depicted in Fig. 2 is highly significant $\left(\mathrm{F}_{7,172}=18.06, P<0.0001\right)$. Males were largest in week 3 (average $\mathrm{PW}=2.18 \mathrm{~cm}$ ) and average body size decreased from week 3 to week 7 . No significant difference (HSD post-hoc tests: $P>0.05$ ) was found for pair wise comparisons of week 4 vs. week 3 , week 5 vs. week 3 and 4, and week 6 vs. weeks 4-10. All remaining pair wise comparisons of weeks 3 to 7 were highly significant (HSD post-hoc tests: $P<0.01$ ). Pair wise comparisons of weeks 3 to 5 vs. weeks 8 to 10 were all significant or highly significant, while all pair wise comparisons of weeks 6 and 7 vs. weeks 8 to 10 were not significant. Average pronotum width remained between 1.74 and $1.77 \mathrm{~cm}$ from week 7 onwards (HSD post-hoc tests: $P>$ 0.90 in all pair wise comparisons for weeks 7 to 10 ).

All four models used to check for a continuous allometry between log-transformed mandible and pronotum width were highly significant, and all detected a positive relationship between the two variables. However, the models had different AIC values (Table 1), with the switch point and the four parameter sigmoidal models giving equally good fits (AIC values of -169.6 and -169.4 , respectively) and the linear regression model the worst. All but one of the five approaches used to check for discontinuity in the data produced models with AIC

TABLE 1. AIC scores and adjusted $\mathrm{R}^{2}$ values of the four models used to check for continuous allometries.

\begin{tabular}{lcc}
\hline Model & AIC score & $\mathrm{R}^{2}$ \\
\hline Switch point regression & -169.6 & 0.81 \\
Four parameter sigmoidal regression & -169.4 & \\
Quadratic model & -159.8 & 0.80 \\
Linear model & -158.4 & 0.79 \\
\hline
\end{tabular}


TABLE 2. AIC scores and adjusted $\mathrm{R}^{2}$ values of the five models used to check for discontinuous allometries.

\begin{tabular}{lcc}
\hline Model & AIC score & $\mathrm{R}^{2}$ \\
\hline Cook \& Bean (2006) modified by Knell (2009) & -356.7 & 0.93 \\
Cook \& Bean (2006) & -343.8 & 0.93 \\
Kotiaho \& Tomkins (2001) & -304.0 & 0.91 \\
Discrete mixtures of regression models & -299.7 & 0.90 \\
Eberhard \& Gutierrez (1991) & -168.8 & 0.81 \\
\hline
\end{tabular}

scores lower than those obtained by the models based on continuity (Table 2). This suggests the existence of discontinuity at the switch point. The method proposed by Cook \& Bean (2006) and its modified version (Knell, 2009) produced a satisfactory separation of the data, since both detected significant discrepancies and changes in slope (Cook \& Bean: discontinuity: $\mathrm{F}_{1,182}=29.19, P<$ 0.0001; slope change: $\mathrm{F}_{1,182}=384.75, P<0.0001$; Cook and Bean modified by Knell: discontinuity: $F_{1,182}=41.36$, $P<0.0001$; slope change: $\mathrm{F}_{1,182}=379.41, P<0.0001$ ), and both highlighted a partial overlap of morphs at the switch point. However, the AIC values obtained using Knell's modified method were markedly lower than those of the unmodified method (Table 2) and therefore Knell's

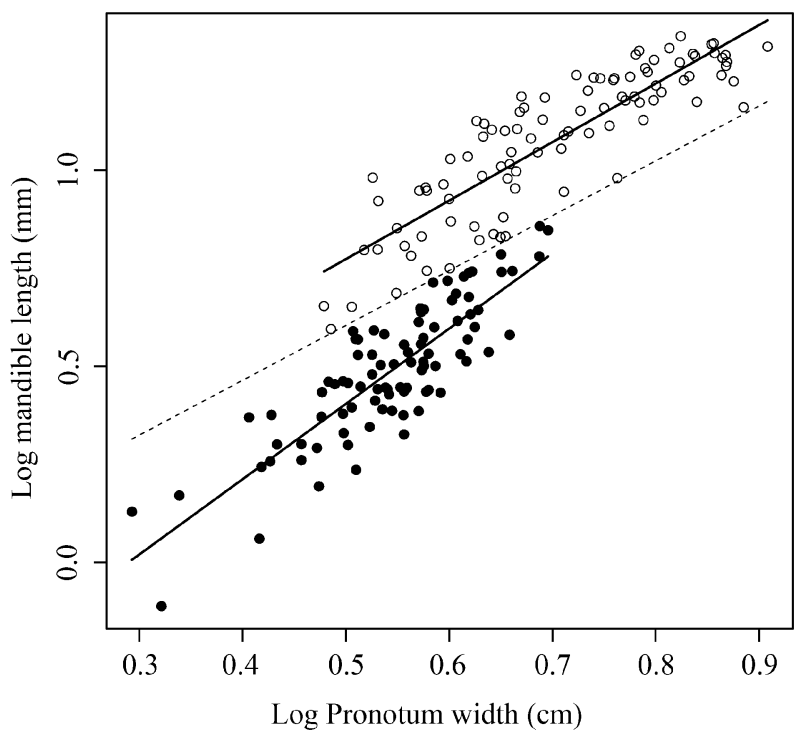

Fig. 3 Separation of morphs obtained by using the method proposed by Cook \& Been (2006) and modified by Knell (2009) to detect discontinuity in data. Solid and open circles indicate the minor and major morphs, respectively. The dashed line indicates the line that best separates the morphs and the solid lines represent the fitted discontinuous model.
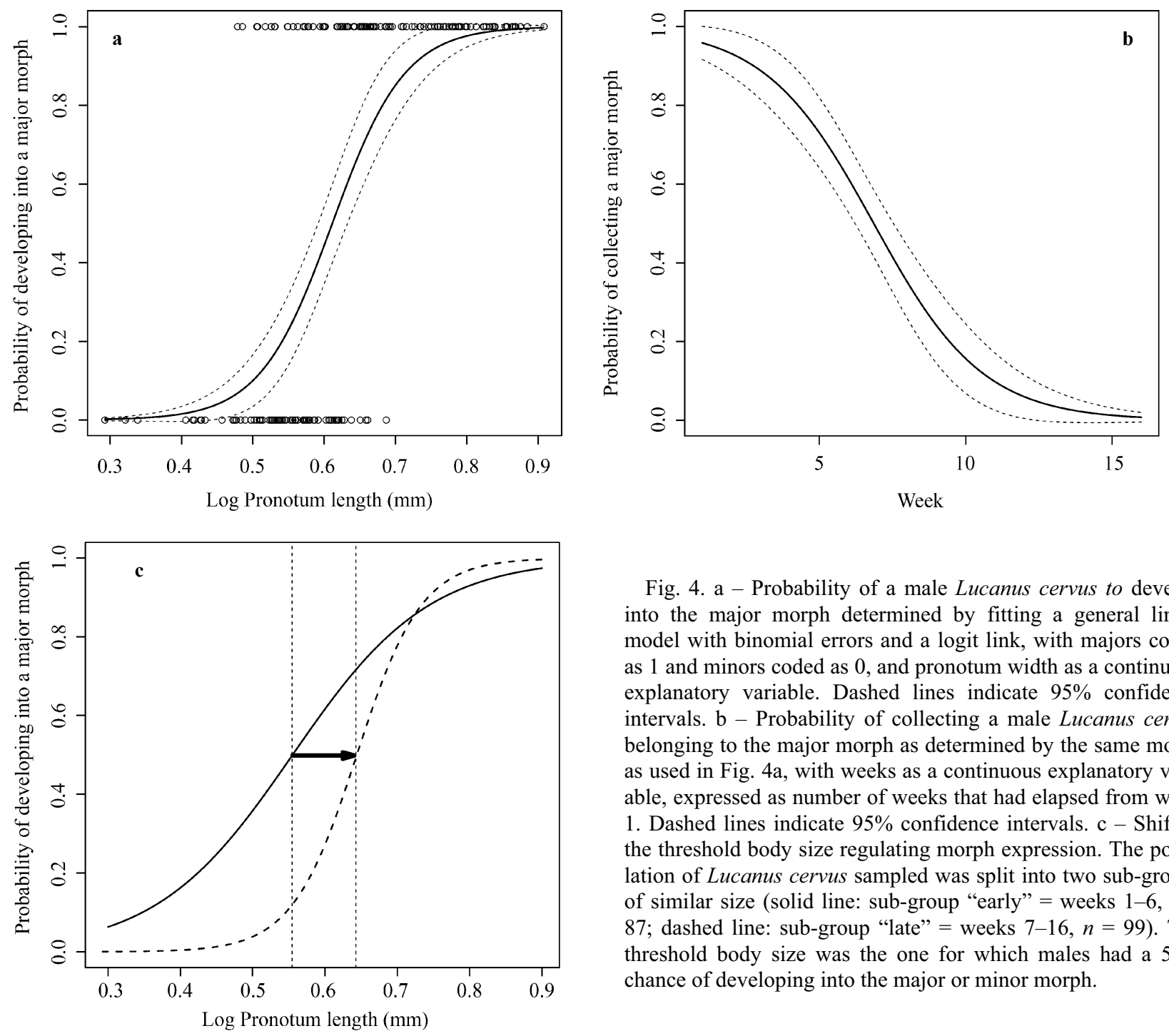

Fig. 4. a - Probability of a male Lucanus cervus to develop into the major morph determined by fitting a general linear model with binomial errors and a logit link, with majors coded as 1 and minors coded as 0 , and pronotum width as a continuous explanatory variable. Dashed lines indicate $95 \%$ confidence intervals. $\mathrm{b}$ - Probability of collecting a male Lucanus cervus belonging to the major morph as determined by the same model as used in Fig. 4a, with weeks as a continuous explanatory variable, expressed as number of weeks that had elapsed from week 1. Dashed lines indicate $95 \%$ confidence intervals. $\mathrm{c}-$ Shift in the threshold body size regulating morph expression. The population of Lucanus cervus sampled was split into two sub-groups of similar size (solid line: sub-group "early" = weeks 1-6, $n=$ 87; dashed line: sub-group "late" = weeks $7-16, n=99$ ). The threshold body size was the one for which males had a $50 \%$ chance of developing into the major or minor morph. 
modified method was used to categorize remains as that of a "major" or "minor" morph (Fig. 3). The probability of developing into a major morph increased with increasing pronotum width (Likelihood Ratio (LR) $\chi^{2}=$ 102.2, df $=1, P<0.0001$, Fig. 4a) and the size threshold for a $50 \%$ chance of developing into the major morph was $\mathrm{PW}=1.84 \mathrm{~cm}$ (0.61 when log-transformed). The number of major morph males collected was high during the first weeks of the study and the logistic model showed that the probability of collecting this morph decreased significantly over time (LR $\chi^{2}=53.70, \mathrm{df}=1, P<0.0001$, Fig. $4 b)$. The threshold body size shifted during the course of the season (Fig. 4c). In the sub-group "early", the size threshold for a $50 \%$ chance of developing into the major morph was $\mathrm{PW}=1.74 \mathrm{~cm}(0.55$ when log-transformed $)$. This value was significantly higher $(\mathrm{PW}=1.90 \mathrm{~cm}, 0.64$ when log-transformed) in the sub-group "late" and the $95 \%$ confidence intervals for the log-transformed data did not overlap (early $=0.45-0.61$; late $=0.62-0.69$ ). The division of the data into two sub-groups containing similar numbers of individuals (weeks $1-6$ vs 7-16) was somewhat arbitrary. In order to test whether other divisions would change the results, the sample was also split into other sub-groups based on weeks 1-5 and weeks 6-16, and weeks 1-7 and weeks 8-16. Both alternative divisions revealed shifts in the threshold body size during the season (result not shown) very similar to that presented in Fig. 4c.

\section{DISCUSSION}

The results presented support the prediction that specimens of $L$. cervus collected late in the season are smaller than those collected early, and confirm the well-known fact that those that emerge early are typically larger than those that emerge late (Sweeney \& Vannote, 1978; Hardersen et al., 1999; Plaistow et al., 2005). However, average size reached a minimum in week 7 (23.-29.vi.2008) and did not decrease any further as the season progressed. This might indicate that L. cervus males are under strong evolutionary pressures not to be less than a certain minimum body size. Harvey \& Gange (2006) show that in L. cervus the optimum male/female size ratio for successful mating is 1.4 and mating attempts are unsuccessful below a ratio of 0.9 . Therefore, males which are smaller than most females are likely to have negligible fitness. Moreover, since the levels of larval juvenile hormone, which plays a key role in the regulation of larval growth and moulting, are known to be sensitive to larval growth (Emlen \& Nijhout, 2000), internal developmental constraints might prevent males from emerging at extremely small body sizes.

The theoretical framework (Rowe \& Ludwig, 1991; Abrams et al., 1996) outlined in the introduction predicts that environmental constraints imposed by the advancing season may influence the development of organisms. There is evidence that changes in ecological conditions influence the horn length - body size allometry of male Onthophagus beetles (Coleoptera: Scarabaeidae). Emlen (1997) provides preliminary evidence that body size dis- tribution of natural populations can change dramatically and states that shifts in the scaling relationship between horn length and body size might be expected whenever the average size of males in the population changes, and that these changes are related to the "optimal" relationship between horn length and body size. Moczek et al. (2002) suggest that the optimal body size at which the switch between two morpho-types occurs may vary as a function of external conditions. Environmental factors that are known to influence allometric functions in beetles are food quality and competition (Emlen, 1997; Moczek, 2002, 2003). In Onthophagus, adult body size and male horn morphology are determined by the quality and quantity of the food that the parents supply their larvae (Moczek, 1998). In contrast, L. cervus larvae are free-living and feed on underground woody debris, mostly of oak (Thomaes et al., 2008). Therefore, the body size they attain at the onset of metamorphosis, which is positively correlated with adult size (Smith, 2002), is not constrained by the volume of larval trophic resources. Adult size and morphology are thus likely to be determined mainly by other environmental conditions. For example, diet quality is known to affect adult body size in Onthophagus acuminatus (Emlen, 1997) and captive bred imagines of $L$. cervus are smaller than those from natural habitats (Rink \& Sinsch, 2011).

It is hypothesized that male L. cervus should invest relatively less in developing mandibles late in the season and thus have relatively small mandibles. The results are consistent with this hypothesis, as the probability of collecting the major morph was high only during the first weeks of the study, approached zero late in the season and the decrease towards zero continued even when average size did not diminish further. This phenotypic plasticity is likely to be related to costs associated with developing large mandibles. Allometric sexual characters of the Lucanidae are believed to be costly (Knell et al., 2003). Resources invested in large ornaments or weapons and in the muscles and other structures needed to wield such weapons are substantial (Kodric-Brown et al., 2006). These costs and associated fitness consequences constrain the sizes of sexually selected structures (Kodric-Brown et al., 2006). In other Scarabaeoidea the expression of exaggerated secondary sexual structures results in a reduction in other body parts such as eyes, antennae and wings (Nijhout \& Emlen, 1998; Emlen, 2001) due to resource allocation trade-offs. In the genus Onthophagus there are negative correlations between relative investment in horns and male copulatory organ (Parzer \& Moczek, 2008) and growth of testes (Simmons \& Emlen, 2006). Likewise, seasonal time constraints, which are presumed to impose developmental constraints (e.g. Rowe \& Ludwig, 1991), appear to have resulted in L. cervus males investing progressively less in costly secondary sexual characters.

Allometric relationships are generally considered to be constant in a given species (e.g. Knell et al., 2003; Kodric-Brown et al., 2006) and invariant during the season (Kodric-Brown et al., 2006; Hongo, 2007). How- 
ever, the comparison of early and late sub-groups of male L. cervus presented here indicate that the threshold body size that regulates morph expression increased during the course of the season, even though average size decreased, an opposite trend to that reported by Emlen (1997) for Onthophagus beetles. Thus, it is clear that, even within the same species, individuals from different populations, reared under different conditions or collected in different seasons, cannot necessarily be expected to share identical allometries. The results presented, along with data provided by Emlen (1997), Plaistow et al. (2005) and Hardersen (2010), indicate that allometric development of exaggerated secondary sexual traits can vary with the advancing season. Hardersen (2010) reports a seasonal shift in relative investment in sexual ornaments in the damselfly, Calopteryx splendens (Harris), which is comparable to the seasonal changes in mandible allometry observed in the present study. Together, these results provide support for a theoretical framework that describes the constraints imposed by the advancing season on the development of insects (Rowe \& Ludwig, 1991; Abrams et al., 1996) and in particular of their exaggerated sexual traits. Furthermore, the fact that resource limitation imposed by the advancing season was so evidently correlated with relative investment in mandible size in $L$. cervus is in keeping with the handicap hypothesis, which assumes that sexually selected traits should show heightened condition dependence (Bonduriansky, 2007).

By using the remains of beetles eaten by predators it was possible to collect a large number of specimens of $L$. cervus, a protected species, without negatively affecting the population. Using a comparable effort to sample live specimens would not have provided a sufficient number of specimens for such an analysis. Differences in the spatial distribution of the remains are unlikely to have influenced the results, as a visual inspection of the distribution of the remains, collected on a weekly basis, did not show any systematic shifts over time.

\section{Alternative explanations}

It is known that predators of insects select prey also based on their sexually selected characters (Svensson \& Friberg, 2007) and that the large males of beetles [e.g. Allomyrina dichotoma Linnaeus (Scarabaeidae)] suffer a slightly higher predatory pressure (Setsuda et al., 1999). Additionally, the behaviour of the major and minor morphs is known to differ in a number of beetle species (e.g. Madewell \& Moczek, 2006; Okada et al., 2007). The interplay of these behavioural differences and predator choice might offer alternative explanations for the data presented. If large males of the major morph are the preferred prey of predators and if this leads to a scarcity of large males later in the season, this could shift the preference of the predator to smaller males. Under these circumstances, differential mortality could be an alternative explanation of the highlighted allometric trend. However, this is unlikely for several reasons.

Firstly, C. corone is an opportunistic predator. There is a seasonal trend in its diet that reflects the abundance of available prey (Berrow et al., 1992; Glutz von Blotzheim
\& Bauer, 1993; Cramp \& Perrins, 1994) and only small beetles $(<3 \mathrm{~mm})$ are avoided (Horgan \& Berrow, 2004). The smallest L. cervus reported in the literature had a body length just over $30 \mathrm{~mm}$ (Clark, 1977; Harvey \& Gange, 2006; Harvey et al., 2011a) and therefore even very small males of $L$. cervus are likely to be eaten by $C$. corone. Furthermore, even if these birds prefer large males, this would not invalidate the findings as long as this preference did not vary systematically throughout the season. Since the lower size threshold of beetles for crows is well below the minimum size of stag beetles, it is unlikely that a shift in prey preference caused the observed pattern. This view is also based on a further analysis of the data. In the first four weeks the smallest specimen collected had a pronotum width of $1.69 \mathrm{~cm}$. In weeks 7 to 10 approximately $27 \%$ of the beetles collected were smaller than $1.69 \mathrm{~cm}$. Thus, in order for the alternative explanation to hold, the preference for eating large beetles would have to be exclusive (i.e. no small males are eaten early in the season), which is an unlikely scenario given the opportunistic nature of the feeding behaviour of $C$. corone. Last but not least, other authors consider collecting dead stag beetles is a valid method that is less biased than museum collections (Kawano, 2000; Harvey \& Gange, 2006) and field-collected remains have successfully been used before to analyze allometric relationships (Lagarde et al. 2005). For these reasons, it is likely that the results reflect a temporal shift in the mandible allometry of $L$. cervus and not an artefact of the sampling procedure.

ACKNOWLEDGEMENTS. We thank F. Mason for the opportunity to carry out this study, E. Minari for providing maps of the reserve and two referees for providing valuable comments. $\mathrm{We}$ are grateful to D. Whitmore for English language correction.

\section{REFERENCES}

Abrams P.A., Leimar O., Nylin S. \& Wiklund C. 1996: The effect of flexible growth rates on optimal sizes and development times in a seasonal environment. Am. Nat. 147: 381-395.

AKaIKe H. 1974: A new look at the statistical model identification. IEEE Trans. Automat. Contr. 19: 716-723.

Berrow S.D., Kelly T.C. \& Myers A.A. 1992: The diet of coastal breeding hooded crows Corvus corone cornix. Ecography 15: 337-346.

BONDURIANSKY R. 2007: The evolution of condition-dependent sexual dimorphism. Evolution 169: 9-19.

Burnham K.P. \& Anderson D.R. 2002: Model Selection and Multimodel Inference: A Practical Information-Theoretic Approach. 2nd ed. Springer, New York, 490 pp.

Campanaro A., Toni I., Hardersen S. \& Grasso D.A. (in press): Monitoring of Lucanus cervus (Coleoptera, Lucanidae) by means of remains of predation. Entomol. Gen.

CLARK J.T. 1977: Aspects of variation in the stag beetle Lucanus cervus (L.) (Coleoptera: Lucanidae). Syst. Entomol. 2: 9-16.

COOK J.M. \& BeAN D. 2006: Cryptic male dimorphism and fighting in a fig wasp. Anim. Behav. 71: 1095-1101.

Cotter S.C., Beveridge M. \& Simmons L.W. 2008: Male morph predicts investment in larval immune function in the dung beetle, Onthophagus taurus. Behav. Ecol. 19: 331-337. 
Cramp S. \& Perrins C.M. 1994: The Birds of the Western Palearctic, Vol. VIII-Crows to Finches. Oxford University Press, Oxford, New York, 899 pp.

De Block M., Campero M. \& Stoks R. 2008: Developmental costs of rapid growth in a damselfly. Ecol. Entomol. 33: 313-318.

EBerhard W.G. \& GUTIERREZ E.E. 1991: Male dimorphism in beetles and earwigs and the question of developmental constraints. Evolution 45: 18-28.

EMLEN D.J. 1996: Artificial selection on horn length-body size allometry in the horned beetle Onthophagus acuminatus (Coleoptera: Scarabaeidae). Evolution 50: 1219-1230.

EMLEN D.J. 1997: Diet alters male horn allometry in the beetle Onthophagus acuminatus (Coleoptera: Scarabaeidae). Proc. R. Soc. Lond. (B) 264: 567-574.

EMLEN D.J. 2001: Costs and the diversification of exaggerated animal structures. Science 291: 1534-1536.

EmLen D.J. \& Nishout H.F. 2000: The development and evolution of exaggerated morphologies in insects. Annu. Rev. Entomol. 45: 661-708.

EmLen D.J., Hunt J. \& Simmons L.W. 2005: Evolution of sexual dimorphism and male dimorphism in the expression of beetle horns: phylogenetic evidence for modularity, evolutionary lability, and constraint. Am. Nat. (Suppl.) 166: S42-S68.

Glutz von Blotzheim U.N. \& BAUER K.M. 1993: Passeriformes (4. Teil): Corvidae - Sturnidae, Rabenvögel, Starenvögel. In Glutz von Blotzheim U.N. (ed.): Handbuch der Vögel Mitteleuropas Band 13-III. AULA, Wiesbaden, pp. 1375-2178.

GotThard K. 2004: Growth strategies and optimal body size in temperate Pararginii butterflies. Int. Comp. Biol. 44: 471-479.

Grün B. \& LeIsch F. 2008: FlexMix version 2: finite mixtures with concomitant variables and varying and constant parameters. J. Stat. Soft. 28: 1-35.

HaRdersen S. 2000: The role of behavioural ecology of damselflies in the use of fluctuating asymmetry as a bioindicator of water pollution. Ecol. Entomol. 25: 45-53.

HARDERSEN S. 2010: Seasonal variation of wing spot allometry in Calopteryx splendens (Odonata: Calopterygidae). Ethol. Ecol. Evol. 22: 365-373.

Hardersen S., Wratten S.D. \& Frampton C.M. 1999: Does carbaryl increase fluctuating asymmetry in damselflies under field conditions? A mesocosm experiment with Xanthocnemis zealandica (Odonata: Zygoptera). J. Appl. Ecol. 36: 534-543.

Harvey D.J. \& Gange A.C. 2006: Size variation and mating success in the stag beetle, Lucanus cervus. Physiol. Entomol. 31: $218-226$.

Harvey D.J., Gange A.C., Hawes C.J. \& Rink M. 2011a: Bionomics and distribution of the stag beetle, Lucanus cervus (L.) across Europe. Insect Conserv. Diver. 4: 23-38.

Harvey D.J., Hawes C.J., Gange A.C., Finch P., Chesmore D. \& FARR I. 2011b: Development of non-invasive monitoring methods for larvae and adults of the stag beetle, Lucanus cervus. Insect Conserv. Diver. 4: 4-14.

Hazel W.N., Smock R. \& Johnson M.D. 1990: A polygenic model for the evolution and maintenance of conditional strategies. Proc. R. Soc. Lond. (B) 242: 181-187.

Hongo Y. 2007: Evolution of male dimorphic allometry in a population of the Japanese horned beetle Trypoxylus dichotomus septentrionalis. Behav. Ecol. Sociobiol. 62: 245-253.

Horgan F.G. \& Berrow S.D. 2004: Hooded Crow foraging from dung pads: implications for the structure of dung beetle assemblages. Biol. Environ. (B) 104: 119-124.

Kawano K. 2000: Genera and allometry in the stag beetle family Lucanidae, Coleoptera. Ann. Entomol. Soc. Am. 93: 198-207.
KNELL R.J. 2009: On the analysis of non-linear allometries. Ecol. Entomol. 34: 1-11.

Knell R.J., Pomfret J.C. \& Tomkins J.L. 2003: The limits of the elaboration: curved allometries reveal the constraints on mandible size in stag beetles. Proc. R. Soc. Lond. (B) 271: 523-528.

Kodric-Brown A., Sibly R.M. \& Brown J.H. 2006: The allometry of ornaments and weapons. Proc. Natl. Acad. Sci. USA 103: $8733-8738$.

Котіано S. \& Tomkins J.L. 2001: The discrimination of alternative male morphologies. Behav. Ecol. 12: 553-557.

Lagarde F., Corbin J., Goujon C. \& Poisbleau M. 2005: Polymorphisme et performances au combat chez les mâles de Lucane cerf-volant (Lucanus cervus). Rev. Ecol. 60: 127-137.

Macagno A.L.M., Pizzo A., Roggero A., Rolando A. \& PalesTRINI C. 2009: Horn polyphenism and related head shape variation in a single-horned dung beetle: Onthophagus (Palaeonthophagus) fracticornis (Preyssler, 1790) (Coleoptera: Scarabaeidae). J. Zool. Syst. Evol. Res. 47: 96-102.

Madewell R. \& MoczeK A.P. 2006: Horn possession reduces maneuverability in the horn-polyphenic beetle, Onthophagus nigriventris. J. Insect Sci. 6: 10 pp.

McLachlan G. \& Peel D. 2000: Finite Mixture Models (Wiley Series in Probability and Statistics). John Wiley and Sons, New York, 456 pp.

MoczeK A.P. 1998: Horn polyphenism in the beetle Onthophagus taurus: larval diet quality and plasticity in parental investment determine adult body size and male horn morphology. Behav. Ecol. 9: 636-641.

MoczeK A.P. 2002: Allometric plasticity in a polyphenic beetle. Ecol. Entomol. 27: 58-67.

MoczeK A.P. 2003: The behavioral ecology of threshold evolution in a polyphenic beetle. Behav. Ecol. 14: 841-854.

Moczek A.P., Hunt J., EmLen D.J. \& Simmons L. 2002: Threshold evolution in exotic populations of a polyphenic beetle. Evol. Ecol. Res. 4: 587-601.

MugGeO V.M.R. 2003: Estimating regression models with unknown break-points. Stat. Med. 22: 3055-3071.

Nijhout H.F. \& EmLen D.J. 1998: Competition among body parts in the development and evolution of insect morphology. Proc. Natl. Acad. Sci. USA 95: 3685-3689.

Ohgushi T. 1991: Temporal decrease in clutch size of the herbivorous lady beetle Epilachna niponica. Jap. J. Entomol. 59: 747-754.

Okada K., Nomura Y. \& Miyatake T. 2007: Relations between allometry, male-male interactions and dispersal in a sap beetle, Librodor japonicus. Anim. Behav. 74: 749-755.

Parzer H.F. \& MoczeK A.P. 2008: Rapid antagonistic coevolution between primary and secondary sexual characters in horned beetles. Evolution 62: 2423-2428.

Paulian R. 1959: Faune de France. Coléoptères Scarabéides. 10th ed. Lechevalier, Paris, $298 \mathrm{pp}$.

Plaistow S.J. \& Siva-Jothy M.T. 1999: The ontogenetic switch between odonate life-history stages: effects on fitness when time and food are limited. Anim. Behav. 58: 659-667.

Plaistow S.J., Tsuchida K., Tsubaki Y. \& Setsuda K. 2005: The effect of seasonal time constraint on development time, body size, condition, and morph determination in the horned beetle Allomyrina dichotoma L. (Coleoptera: Scarabaeidae). Ecol. Entomol. 30: 692-699.

RINK M. \& SINSCH U. 2011: Warm summers negatively affect duration of activity period and condition of adult stag beetles (Lucanus cervus). Insect Conserv. Diver. 4: 15-22. 
Rolff J., Van de Meutter F. \& Stoks R. 2004: Time constraints decouple age and size at maturity and physiological traits. Am. Nat. 164: 559-565.

Rowe L. \& Ludwig D. 1991: Size and timing of metamorphosis in complex life histories, time constraints and variation. Ecology 72: 413-427.

Savalli U.M. \& Fox C.W. 1998: Sexual selection and the fitness consequences of male body size in the seed beetle Stator limbatus. Anim. Behav. 55: 473-483.

Setsuda K., Tsuchida K., Watanabe H., Kakei Y. \& Yamada Y. 1999: Size dependent predatory pressure in the Japanese horned beetle, Allomyrina dichotoma L. (Coleoptera: Scarabaeidae). J. Ethol. 17: 73-77.

Simmons L.W. \& EmLen D.J. 2006: Evolutionary trade-off between weapons and testes. Proc. Natl. Acad. Sci. USA 103: 16346-16351.

Simmons L.W. \& PARKer G.A. 1992: Individual variation in sperm competition success of yellow dung flies, Scathophaga stercoraria. Evolution 46: 366-375.

Sмiтн R.J. 2002: Effect of larval body size on overwinter survival and emerging adult size in the burying beetle, Nicrophorus investigator. Can. J. Zool. 80: 1588-1593.
Sokolovska N., Rowe L. \& Johansson F. 2000: Fitness and body size in mature odonates. Ecol. Entomol. 25: 239-248.

Svensson E.I. \& Friberg M. 2007: Selective predation on wing morphology in sympatric damselflies. Am. Nat. 7: 101-112.

Sweeney B.W. \& VAnNote R.L. 1978: Size variation and the distribution of hemimetabolous acquatic insects: two thermal equilibrium hypotheses. Science 200: 444-446.

Thomaes A., Kervyn T., Beck O. \& Cammaerts R. 2008: Distribution of Lucanus cervus (Coleoptera: Lucanidae) in Belgium: surviving in a changing landscape. Rev. Ecol. 63: 139-144.

Tomkins J.L. \& Hazel W. 2007: The status of the conditional evolutionarily stable strategy. Trends Ecol. Evol. 22: 522-528.

Tomkins J.L., LeBas N.R., Unrug J. \& Radwan J. 2004: Testing the status-dependent ESS: population variation in fighter expression in the mite Sancassania berlesei. J. Evol. Biol. 17: 1377-1388.

Tseng M. 2003: Life-history responses of a mayfly to seasonal constraints and predation risk. Ecol. Entomol. 28: 119-123.

Zahavi A. 1975: Mate selection - a selection for a handicap. $J$. Theor. Biol. 53: 205-213.

Received June 16, 2010; revised and accepted March 30, 2011 